\title{
Konik Işınlı Bilgisayarlı Tomografi ile Yaş Tayininde Diş Seçimi: Diş Kadranları Simetrik mi?
}

\author{
Ender İDMAN 모, Birsay GÜMRÜ
}

$\ddot{O} z$

Amaç: Dental radyografilerin yaş tayininde güvenle kullanılabileceği yapılan çalışmalarla ortaya konmuş olup üç boyutlu görüntüleme yöntemlerinin son yıllardaki gelişimi ile bu alanda pek çok yeni çalışma yapılmıştır. Yapılan çalışmalarda, çenelerin sağ ve sol kadranları arasında belirgin simetri olduğu öne sürülmektedir. Bu çalışmanın amacı; mandibular premolar dişlerdeki yapısal değişikliklerin konik ışınlı bilgisayarlı tomografi (KIBT) görüntülerinde farklı radyolojik yaş tayini yöntemleri ile değerlendirilerek sağ ve sol kadranlar arasında farklılık olup olmadığının araştırılmasıdır.

Gereç ve Yöntem: Mandibular sağ ve sol 1. ve 2. premolar dişlerin mevcut olduğu yüksek diagnostik kaliteye sahip 50 adet KIBT görüntüsünde; mandibular premolar dişlerin tümünde yapısal değişiklikler görsel olarak (modifiye Gustafson metodu), lineer ölçümlerle (Kvaal yöntemi) ve hacim ölçümleriyle (pulpa/ diş hacim oranı yöntemi) değerlendirilmiştir. Elde edilen veriler istatistiksel olarak değerlendirilmiştir.

Bulgular: Yapılan tüm değerlendirmelerde, premolar dişlerin her biri için oluşturulan regresyon modelleri istatistiksel olarak anlamlı $(\mathrm{p}<0,001)$ bulunmuştur. Modifiye Gustafson metodu kullanılarak gerçekleştirilen görsel değerlendirmelerde $45(\mathrm{R}=0,734)$ ve $44(\mathrm{R}=0,707)$ no'lu dişlerin, Kvaal yöntemi kullanılarak gerçekleştirilen lineer ölçümlerde $35 \quad(R=0,385)$ ve $44(\mathrm{R}=0,375)$ no'lu dişlerin, pulpa/diş hacim oranı yöntemi kullanılarak gerçekleştirilen değerlendirmelerde ise $35(\mathrm{R}=0,461)$ ve $34(R=0,420)$ no'lu dişlerin yaş ile daha yüksek korelasyon gösterdikleri sonucuna ulaşılmıştır.

Birsay GÜMRÜ (四)

Marmara Üniversitesi Başıbüyük Sağllk Yerleşkesi, Dişhekimliği Fakültesi, Ăgız, Diş ve Çene Radyolojisi Anabilim Dalı, Başıbüyük Yolu 9/3 34854 Başıüyü̈k / Maltepe / Istanbul

Telefon: 02164211621 , Fax: 02164210291

bgumru@marmara.edu.tr

Ender İDMN

Marmara Üniversitesi Diş Hekimliği Fakültesi, Ağız, Diş ve Çene Radyolojisi Anabilim Dal, İstanbul, Türkiye

Submitted / Gönderilme: 10.09.2019 Accepted / Kabul: 27.12.2019
Sonuç: Yaş tayini konusunda daha önce yapılan ve sağ-sol kadranlar arasında farklılık olmadığını öne süren çalışmaların aksine, çalışmamızda sağ-sol kadranlar arasında farklılık olduğu tespit edilmiştir.

Anahtar kelimeler: konik 1şınlı bilgisayarlı tomografi, yaş tayini, maksilla, mandibula, diş kadranı

\section{Abstract}

Objective: It has been demonstrated that dental radiographs can be used reliably in age estimation and in recent years many studies have been conducted in this field with the development of threedimensional imaging methods. Previous studies suggested that the use of teeth on the right or left side has no effect on age estimation. The aim of this study was to evaluate the structural changes in mandibular premolar teeth in cone beam computed tomography (CBCT) images by using different radiological age estimation methods to investigate whether there is a difference between right and left quadrants.

Methods: In 50 high diagnostic quality CBCT images with mandibular right and left 1st and 2nd premolars, the structural changes in all premolar teeth were evaluated by visual assessments using a modification of Gustafson method, by linear measurements using Kvaal method, and by volumetric measurements using pulp/ tooth volume ratio method. The data obtained were evaluated statistically.

Results: In all evaluations, the regression models for each premolar teeth were statistically significant $(p<0.001)$. In the visual evaluations carried out using the modified Gustafson method teeth \#45 $(\mathrm{R}=0.734)$ and \#44 $(\mathrm{R}=0.707)$, in the linear measurements carried out using Kvaal method teeth \#35 ( $\mathrm{R}=0.385)$ and \#44 $(\mathrm{R}=0.375)$, and in the volumetric evaluations carried out using pulp/tooth volume ratio method teeth \#35 ( $\mathrm{R}=0.461)$ and \#34 $(\mathrm{R}=0.420)$ showed higher correlation with age.

Conclusions: Contrary to the previous radiological age estimation studies suggesting that the use of teeth on the right or left side has no effect on age estimation, the results of our study established that there were differences between the right and left quadrants.

Keywords: cone beam computed tomography, age estimation, maxilla, mandible, quadrant 


\section{GİRiş}

Bireylerin yaşadıkları toplumdaki diğer bireylerden ayırt edilebilmelerinde faydalanılan bilgi bütününe "kimlik", adli tıp ve antropolojik incelemeler başta olmak üzere çeşitli nedenlerden dolayı bireye özgü olan bu bilgilerin ortaya çıkarılmasına ise "kimlik tespiti" denir (1).

Cinsiyet, boy, vücut ağırlığı, saç-cilt-göz rengi, parmak izi, kemikler ve dişler gibi kişinin tıbbi kimliğini meydana getiren fiziksel özelliklerden biri de yaş olup kişinin yaşının belirlenmesi, kimlik tespitinde en önemli basamağ 1 teşkil etmektedir. Güvenilir kimlik bilgileri olmayan bireylerde cezai ve hukuki sorumluluğun belirlenmesinde, okul-iş-askere alınma-emeklilik gibi yaş sınırı olan bazı durumlarda, terör olayları, ulaşım araçları kazaları ve afet durumlarındaki toplu ölüm vakalarında yaş tayinine ihtiyaç duyulmaktadır (2). Ülkemizde özellikle kırsal alanlarda nüfus kayıtlarının aksatılması, aynı aileye mensup bireylerin kimlik bilgilerinin birbirlerinin üzerine kaydedilmesi gibi yanlış uygulamalar sonucunda bireylerin kronolojik yaşları ile kimlik yaşları arasında uyumsuzluklar görülebilmektedir (3).

Yaş tayininde en sık kullanılan yöntemler, kemik ve diş geliş̧iminin değerlendirildiği yöntemlerdir. Kemik gelişimi temelde kemiklerin epifiz sınırlarının kapanma derecelerine göre değerlendirilmekte, kemik gelişimi fizyolojik olarak devam eden bireylerde kemik yaşının kronolojik yaşa eşit olduğu savunulmaktadır (4). Bireylerin kemik gelişiminde coğrafi ve çevresel faktörler, konjenital bozukluklar, sendromlar, endokrin bozukluklar, beslenme bozuklukları ve ırk gibi çeşitli faktörler rol oynamaktadır (5). Dişler; gerek genetik ve çevresel etkenlerden diğer organlara oranla daha az etkilenmeleri, gerekse sert yapısal özelliklerinden dolayı mekanik, kimyasal, fiziksel etkilere ve zamana karşı dirençli olmaları ve morfolojik yapılarını uzun süre korumaları nedeniyle adli tıpta ve antropolojide yaş tayininde değerli bilgiler sağlamaktadır $(6,7)$.

Dişlerden yaş tayini amacıyla geliştirilen yöntemler genel olarak histolojik, morfolojik ve radyografik yöntemler olarak sınıflandırılabilir. Radyografik yöntemler; materyalin bütünlüğüne zarar vermemesi, yaşayan bireylerde de inceleme imkanı sunması, hızl, kolay uygulanabilir ve ekonomik yöntemler olması nedeniyle avantajlıdır $(8,9)$. Dental radyografilerin yaş tayininde güvenle kullanılabileceği yapılan çalışmalarla da ortaya konmuştur $(8,10)$.
Literatürde, radyolojik yaş tayini çalışmalarında çoğunlukla iki boyutlu görüntüleme yöntemleri olan periapikal ve panoramik radyografilerin kullanıldığ görülmektedir $(8,11)$. Teknolojinin gelişmesiyle birlikte son yıllarda mikro-bilgisayarlı tomografi (mikro-BT), multi-detektörlü bilgisayarlı tomografi (MDBT) veya konik 1şınlı bilgisayarlı tomografi (KIBT) gibi üç boyutlu (3D) görüntüleme sistemlerindeki gelişim, dental yaş tayini alanında yeni ve farklı birçok çalışmanın yapılmasına olanak sağlamıştır (12-17).

Gerçekleştirilen yaş tayini çalışmalarında, sağ ve sol kadranlardaki dişlerin kullanımının yaş tayinine etkisi olmadığı belirtilmektedir (8). Bu nedenle; yapılan çok sayıdaki yaş tayini çalışmasında kullanılacak dişin seçimi için pilot çalışma yapılmadığı görülmektedir $(8,18,19)$.

$\mathrm{Bu}$ bilgiler 1şı̆̆ında; bu çalışmanın amacı, KIBT görüntülerinde mandibular premolar dişlerdeki yapısal değişikliklerin üç farklı radyolojik yaş tayini yöntemi ile değerlendirilerek sağ ve sol kadranlar arasında farklılık olup olmadığının araştırılmasıdır.

\section{GEREÇ VE YÖNTEM}

$\mathrm{Bu}$ çalışma, Marmara Üniversitesi Tıp Fakültesi Klinik Araştırmalar Etik Kurulu Başkanlığı tarafından 09.2017.539 protokol numarası ile onaylanmış ve Marmara Üniversitesi Bilimsel Araştırma Projeleri Birimi tarafından SAG-CDUP-131.217.0660 proje numarası ile desteklenmiştir.

\section{Çalışma Grubu}

Marmara Üniversitesi Diş Hekimliği Fakültesi Ağız, Diş ve Çene Radyolojisi Anabilim Dalı Radyoloji Birimi'ne Mayıs 2012 - Eylül 2017 tarihleri arasında başvuran ve çeşitli nedenlerle radyolojik değerlendirmeleri (ortodontik değerlendirme, temporomandibular eklem problemleri ve implant planlaması vb.) yapılan hastaların KIBT görüntüleri (Planmeca Promax 3D Mid, Planmeca Oy, Helsinki, Finlandiya) retrospektif olarak incelenmiş ve çalışmaya dahil olma kriterlerine uyan 50 hastanın yüksek diagnostik kaliteye sahip KIBT görüntüleri çalışma grubuna dahil edilmiştir.

Çalışma grubuna dahil edilme kriterleri; tomografik görüntü sahibi hastanın 18 ve üzeri yaşta olması, mandibular premolar dişlerin tümünün mevcut, tamamen sürmüş, kök gelişimlerinin tamamlanmış ve pozisyonlarının düzgün 
olması, mandibular premolar dişlerde çürük, fraktür, periapikal patoloji, restorasyon, kök-kanal dolgusu, pulpa kalsifikasyonu, pulpa taşı bulunmaması olarak belirlenmiş olup bu kriterlere uymayan görüntüler çalışma dışı bırakılmıştır.

\section{Radyolojik Görsel Değerlendirmeler (Modifiye Gustaf- son Metodu)}

KIBT görüntülerinden elde edilen panoramik yapılandırma görüntülerinde mandibular sağ ve sol premolar dişlerdeki atrisyon miktarı, sekonder dentin kalınlığ1 ve periodontal doku kaybı kriterleri Gustafson'un (11) Koh ve ark. (20) tarafından modifiye edilen sınıflaması ile değerlendirilmiş ve sınıflandırılmıştır.

\section{Radyolojik Lineer Ölçümler (Kvaal Yöntemi)}

KIBT görüntülerinden elde edilen panoramik yapılandırma görüntülerinde mandibular sağ ve sol premolar dişlerde Kvaal ve ark. (8) tarafindan belirtilen lineer ölçümler gerçekleştirilmiştir.

Maksimum diş uzunluğu, maksimum pulpa uzunluğu, maksimum kök uzunluğu, mine-sement birleşimi hizasında kök genişliği, mine-sement birleşimi hizasında pulpa genişliği, mine-sement birleşimi ve kök apikali ortasında (kökün orta noktasında) kök genişliği, mine-sement birleşimi ve kök apikali ortasında (kökün orta noktasında) pulpa genişliği, mine-sement birleşimi ile kökün orta noktasının ortasındaki kök genişliği, mine-sement birleşimi ile kökün orta noktasının ortasındaki pulpa genişliği ölçümleri gerçekleştirilmiştir. Bu lineer uzunluk ve genişlik ölçümlerinden diş/kök uzunluk (T), pulpa/kök uzunluk (P), pulpa/diş uzunluk (R), mine-sement birleşimi hizasındaki pulpa/kök genişlik (A), kökün orta noktasındaki pulpa/kök genişlik (C), mine-sement birleşimi ile kökün orta noktası arasındaki mesafenin ortasındaki kök/pulpa genişlik (B) oranları elde edilmiştir. Tüm oranların ortalama değeri (M), $B$ ve $C$ genişlik oranlarının ortalama değeri $(W), P$ ve $R$ uzunluk oranlarının ortalama değeri (L) saptanmıştır.

\section{Radyolojik Hacim Ölçümleri (Pulpa/Diş Hacim Oranı Yöntemi)}

Pulpa/diş hacim oranı ölçümleri için; KIBT görüntülerinin DICOM formatında 3D-Doctor (Able Software Corp., Lexington, MA, Amerika Birleşik Devletleri) programına aktarılmasını takiben görüntülerdeki voksel boyutu orijinal
KIBT görüntüsündeki voksel boyutuna göre kalibre edilmiştir. Dişlerin ve pulpalarının ayrı ayrı elde edilen hacimleri program aracılığı ile $\mathrm{mm}^{3}$ cinsinden ölçülerek pulpa/diş hacim oranları hesaplanmıştır.

\section{İstatistiksel Analiz}

Çalışma başlangıcında kronolojik yaşları bilinmeyen hastaların kronolojik yaşları, tüm değerlendirmeler ve ölçümler yapıldıktan sonra KIBT görüntülerinin elde edildiği tarihten hastaların doğum tarihlerinin çıkartılması ile hesaplanmış ve kaydedilmiştir. Tüm ölçümler hastaların kronolojik yaşlarını bilmeyen tek bir gözlemci (Eİ) tarafindan yapılmıştır.

İstatistiksel değerlendirmelerde Statistical Package for Social Sciences Programı (SPSS 15.0, SPSS Inc., Chicago, Amerika Birleşik Devletleri) kullanılmıştır. Elde edilen verilerle, yaş tayininde kullanılabilecek çoklu ve tekli regresyon modelleri oluşturulmuştur.

\section{BULGULAR}

\section{Radyolojik Görsel Değerlendirmeler (Modifiye Gustafson Metodu)}

Genel olarak mandibular premolar dişlerin her biri için atrisyon miktarı, periodontal doku kaybı ve sekonder dentin kalınlığı değişkenleri kullanılarak oluşturulan çoklu regresyon modellerinin tümü istatistiksel olarak anlamlı olup $(p<0,001)$ en yüksek korelasyon katsayısı ve açıklayııılık katsayısı değerleri $\left(\mathrm{R}=0,734, \mathrm{R}^{2}=0,538\right) 45$ no'lu diş için elde edilmiştir (Tablo 1).

Tablo 1. Modifiye Gustafson metodu kullanılarak 34, 35, 44 ve 45 no'lu dişler için gerçekleştirilen çoklu regresyon analizi sonuçları

\begin{tabular}{|c|c|c|c|c|}
\hline $\begin{array}{l}\text { Diş } \\
\text { no }\end{array}$ & Regresyon modeli & $\mathbf{R}$ & $\mathbf{R}^{2}$ & $\mathbf{S E}$ \\
\hline $\mathbf{3 4}$ & $\begin{array}{c}\text { Yaş }=23,528+10,146 \times \mathrm{AT}+ \\
1,671 \times \mathrm{SD}+6,557 \times \mathrm{PD}\end{array}$ & 0,571 & 0,326 & 11,531 \\
\hline $\mathbf{3 5}$ & $\begin{array}{c}\text { Yaş }=23,576+13,046 \times \mathrm{AT}+ \\
1,491 \times \mathrm{SD}+6,548 \times \mathrm{PD}\end{array}$ & 0,591 & 0,350 & 11,328 \\
\hline $\mathbf{4 4}$ & $\begin{array}{c}\text { Yaş }=19,505+13,655 \times \mathrm{AT}+ \\
3,478 \times \mathrm{SD}+7,746 \times \mathrm{PD}\end{array}$ & 0,707 & 0,499 & 9,939 \\
\hline $\mathbf{4 5}$ & $\begin{array}{c}\text { Yaş }=25,838+11,524 \times \mathrm{AT}- \\
2,019 \times \mathrm{SD}+10,834 \times \mathrm{PD}\end{array}$ & 0,734 & 0,538 & 9,543 \\
\hline
\end{tabular}

$\boldsymbol{R}$ : korelasyon katsayısı, $\boldsymbol{R}^{2}$ : açıklayıcılık katsayısı, $\mathbf{S E}$ : Standart hata orani

AT: atrisyon miktarı, SD: sekonder dentin kalınlığ kaybı miktarı 


\section{Radyolojik Lineer Ölçümler (Kvaal Yöntemi)}

Mandibular premolar dişlerde gerçekleştirilen lineer ölçümler kullanılarak elde edilen T, P, R, A, C, B, M, W ve $L$ değerlerinin yaş ile ilişkisi Pearson korelasyon analizi ile test edilmiştir. Yaş ile en yüksek korelasyonu; sırasıyla $\mathrm{B}(\mathrm{R}=0,389), \mathrm{C}(\mathrm{R}=0,294)$ ve $\mathrm{T}(\mathrm{R}=0,074)$ değişkenlerinin gösterdiği bulunmuştur.

$\mathrm{T}$, B ve $\mathrm{C}$ değişkenleri kullanılarak her bir diş için oluşturulan çoklu regresyon modellerinin tümü istatistiksel olarak anlamlı olup $(p<0,001)$ en yüksek korelasyon katsayısı ve açıklayıcılık katsayısı değerleri $(\mathrm{R}=0,385$, $\mathrm{R}^{2}=0,148$ ) 35 no'lu diş için elde edilmiştir (Tablo 2).

Tablo 2. Kvaal metodu kullanılarak 34, 35, 44 ve 45 no'lu dişler için gerçekleştirilen çoklu regresyon analizi sonuçları

\begin{tabular}{|c|c|c|c|c|}
\hline Diş no & Regresyon modeli & $\mathbf{R}$ & $\mathbf{R}^{2}$ & SE \\
\hline 34 & $\begin{array}{c}\text { Yaş }=27,508-49,442 \times \mathrm{B}-26,885 \\
\times \mathrm{T}+21,663 \times \mathrm{C}\end{array}$ & 0,322 & 0,104 & 13,969 \\
\hline 35 & $\begin{array}{c}\text { Yaş }=47,634-18,229 \times \mathrm{B}+32,480 \\
\text { x T }+27,242 \times \mathrm{C}\end{array}$ & 0,385 & 0,148 & 13,618 \\
\hline 44 & $\begin{array}{c}\text { Yaş= } 39,069-63,066 \text { x B }+32,480 \\
\text { x T }+27,242 \times \text { x }\end{array}$ & 0,375 & 0,141 & 13,679 \\
\hline 45 & $\begin{array}{c}\text { Yaş }=11,597-17,003 \times \mathrm{B}+9,052 \times \\
\mathrm{T}+8,791 \times \mathrm{C}\end{array}$ & 0,289 & 0,083 & 14,128 \\
\hline
\end{tabular}

$\boldsymbol{R}$ : korelasyon katsayısı, R2: açıklayıcılık katsayısı, SE: Standart hata oranı

T: Diş/kök uzunluk oran1, B: Mine-sement birleşimi ile kökün orta noktası arasındaki mesafenin ortasındaki kök/pulpa genişlik oranı, C: Kökün orta noktasındaki pulpa-kök genişlik oranı

\section{Radyolojik Hacim Ölçümleri (Pulpa/Diş Hacim Oranı Yöntemi)}

Mandibular premolar dişlerin her biri için pulpa/diş hacim oranı (PT) ile yaş arasında kurulan regresyon modelleri istatistiksel olarak anlamlı olup $(\mathrm{p}<0,001)$ en yüksek korelasyon katsayısı ve açıklayıcılık katsayısı değerleri ( $\left.R=0,461, R^{2}=0,212\right) 35$ no'lu diş için elde edilmiştir (Tablo 3).

Tablo 3. Pulpa/diş hacim oranı yöntemi kullanılarak 34, 35, 44 ve 45 no'lu dişler için gerçekleştirilen basit regresyon analizi sonuçları

\begin{tabular}{|c|c|c|c|c|}
\hline Diş No. & Regresyon modeli & R & $\mathbf{R}^{2}$ & S.E. \\
\hline 34 & Yaş=52,552-482,883 x PT & 0,420 & 0,176 & 12,552 \\
\hline 35 & Yaş $=53,241-540,185 \times$ PT & 0,461 & 0,212 & 12,274 \\
\hline 44 & Yaş=48,712-423,096 x PT & 0,364 & 0,133 & 12,879 \\
\hline 45 & Yaş=51,038-501,591 x PT & 0,366 & 0,134 & 12,868 \\
\hline
\end{tabular}

$\boldsymbol{R}$ : korelasyon katsayısı, R2: açıklayıcılık katsayısı, SE: Standart hata oran

PT: Pulpa/diş hacim oranı

\section{TARTIŞMA}

Primer dentin oluşumunun tamamlanmasını takiben pulpa sinırları çevresinde yaşam boyu devam eden sekonder dentin yapımı; abrazyon, atrisyon, çürük, pulpa odasındaki osmotik basınç değişimi ve fizyolojik yaşlanma gibi patolojik veya fizyolojik nedenlerden etkilenerek pulpa odası hacminde değişikliğe neden olmaktadır. Yaş ile birlikte pulpa boyutlarında meydana gelen bu değişikliğin çeşitli yöntemlerle değerlendirilmesi dental yaş tayini çalışmalarında önemli bilgiler sunmaktadır $(14,15)$.

Dişlerde meydana gelen yapısal değişikliklerin yaş tayini çalışmalarında kullanılabileceğini öne süren ilk araştırmacı olan Gosta Gustafson (11); atrisyon, periodontitis, sekonder dentin oluşumu, sement apozisyonu, kök transparanlığı ve kök rezorpsiyonu parametrelerinde yaşla birlikte meydana gelen değişiklikleri 4 evrede skorlamış ve bir regresyon modeli elde etmiştir. Daha sonra çok sayıda çalışmacı tarafından Gustafson'un belirlediği kriterlerden esinlenerek oluşturulan modifiye metotlar kullanılarak dental yaş tayini çalışmaları gerçekleştirilmiştir (20-27). Yapılan literatür taramasında, Gustafson metodu veya modifikasyonları kullanılarak gerçekleştirilen çalışmaların iki boyutlu görüntüleme yöntemleri olan periapikal veya panoramik radyografiler kullanılarak gerçekleştirildiği ve sağ ve sol kadranlardaki dişler arasında yaş tayini açısından farklılık olup olmadığının araştırılmadığı görülmektedir $(11,26,28$, 29).

Modifiye Gustafson metodunun kullanıldığ 1 tek bir çalışmada 3D görüntüleme yöntemi olan KIBT kullanıldığı saptanmıştır (20). Koh ve ark. (20), Malezya ve Çin popülasyonunda 284 KIBT görüntüsü kullanarak mandibular 1. premolar dişlerde gerçekleştirdikleri çalışmalarında Gustafson'un 6 parametresinden 3 tanesini (atrisyon, sekonder dentin formasyonu ve periodontal doku kaybı) kullanmışlar ve sol kadrandaki premolar dişlerin, sağ kadrandakilere oranla kronolojik yaş ile daha yüksek korelasyon gösterdiklerini belirlemişlerdir.

Çalışmamızda Koh ve ark.'ın (20) aksine görsel değerlendirmeler kullanılarak yapılan yaş tayininde sağ kadrandaki premolar dişlerin yaş ile daha yüksek korelasyon gösterdikleri görülmüştür.

Kvaal ve ark. (8), ilerleyen yaş ile birlikte pulpa boyutlarında meydana gelen değişimi iki boyutlu periapikal radyografilerde diş ve pulpanın belirli bölgelerinden elde ettikleri uzunluk ve genişlik lineer ölçümleri ile değerlendiren ilk araştırmacılardır. Yaş ile 
en yüksek korelasyonu; maksiller santral kesici, lateral kesici ve 2. premolar dişler ile mandibular lateral kesici, kanin ve 1. premolar dişlerin gösterdiğini saptamış ve değerlendirmelerde bu dişlerin kullanılmasına karar vermişlerdir. Sağ ve sol kadranlar arasında anlamlı farklılık bulamadıklarından dolayı herhangi bir kadrandaki dişlerin değerlendirmede kullanılabileceğini de belirtmişlerdir (8). Yapılan literatür taraması sonucunda; Kvaal yöntemi veya modifikasyonları kullanılarak gerek iki boyutlu, gerekse 3D görüntüleme yöntemleri ile gerçekleştirilen radyolojik yaş tayini çalışmalarında sağ ve sol kadranlardaki dişler arasında yaş tayini açısından farklılık olup olmadığının araştırılmadığı görülmektedir (17, 19, 30-34).

Çalışmamızda mandibular premolar dişlerde radyolojik lineer ölçümler ile yapılan yaş tayininde 35 ve 44 numaralı dişlerin yaş ile daha yüksek korelasyon gösterdikleri bulunmuştur.

Yaşa bağlı değişiklikler arasında önemli bir parametre olarak görülen sekonder dentin birikimi, pulpa hacminde azalmaya neden olmaktadır. Çevresel faktörlerden en az etkilenen sekonder dentin birikimi, yaş tayini çalışmalarında önemli bilgiler sunmaktadır $(15,35)$.

Panoramik ve periapikal radyografiler gibi iki boyutlu görüntüleme yöntemlerinde süperpozisyon, eşit olmayan magnifikasyon ve ölçümlerin sadece bir yüzeyden yapılabilmesi gibi değerlendirmeyi zorlaştıran faktörler söz konusudur (36). Son y1llarda, 3D görüntüleme yöntemleri kullanılarak pulpa/diş hacim oranlarının hesaplandığ1 yaş tayini çalışmaları gerçekleştirilmektedir. Sekonder dentin birikiminin pulpanın her tarafinda homojen olarak gerçekleşmemesi, 3D görüntüleme tekniklerinde iki boyutlu görüntüleme tekniklerinin dezavantajlarının söz konusu olmaması ve geliştirilen özel yazılımlar sayesinde pulpa ve diş hacim ölçümlerinin gerçekleştirilebilmesi yaş tayini çalışmalarında 3D görüntülemenin kullanımının artmasına neden olmuştur $(14,15,36)$.

Yapılan literatür taramasında; KIBT görüntülerinde pulpa/diş hacim ölçümü ile yapılan radyolojik yaş tayini çalışmalarında sağ ve sol kadranlardaki dişler arasında yaş tayini açısından farklılık olup olmadığının araştırılmadığ 1 görülmektedir (14-17, 36). Asif ve ark.; Malezya popülasyonunda 300 KIBT görüntüsünde maksiller sağ ve sol kanin ve maksiller sağ santral kesici dişlerin pulpa/ diş hacim oranının yaş ile ilişkisini değerlendirdikleri çalışmalarında maksiller sağ ve sol kanin dişlerin yaş ile korelasyon değerlerinde anlamlı bir farklılık bulunmadığını belirtmişlerdir (36).
Çalışmamızda mandibular premolar dişlerde pulpa/diş hacim oranları kullanılarak yapılan yaş tayininde Asif ve ark.' 'n aksine sol kadrandaki dişlerin yaş ile daha yüksek korelasyon gösterdikleri görülmüştür.

\section{SONUÇ}

Yaş tayini konusunda daha önce farklı radyolojik yaş tayini yöntemleri kullanılarak gerçekleştirilen ve sağ-sol kadranlar arasında farklılık olmadığını öne süren çalışmaların aksine çalışmamızda sağ-sol kadranlar arasında farklılık olduğu tespit edilmiştir. Bu nedenle, radyolojik yaş tayini çalışmalarında hangi yöntem kullanılırsa kullanılsın çalışmada kullanılacak dişin seçimi için pilot çalışma yapılması gerektiği sonucuna varılmıştır.

\section{KAYNAKLAR}

1. Teke HY, Duran S, Bilge Y: Radyolojik metotların adli antropolojide kullanımı. Türkiye Klinikleri J Foren MedSpecial Topics 2017;3:108-112.

2. Baransel Isır A, Dülger HE: 1998-2005 yılları arasında Gaziantep Üniversitesi Adli Tıp Anabilim Dalında raporlandırılan yaş tayini olgularının irdelenmesi. Turkiye Klinikleri J Foren Med 2007;4:1-6.

3. Atılgan M, Akkoyun M: Akdeniz Üniversitesi Tıp Fakültesi Adli Tıp Anabilim Dalı'ndan yaş tayini istenen olguların değerlendirilmesi. Adli Tıp Bülteni 2017;22:34-39.

4. Demirkıran DS, Çelikel A, Zeren C, Arslan MM: Yaş tespitinde kullanılan yöntemler. Dicle Tip Derg / Dicle Med J 2014;41:238-243.

5. Schmeling A, Olze A, Pynn BR, Kraul V, Schulz R, Heinecke A, Pfeiffer H: Dental age estimation based on third molar eruption in First Nation people of Canada. J Forensic Odontostomatol 2010;28:32-38.

6. Kringsholm B, Jakobsen J, Sejrsen B, Gregersen M: Unidentified bodies/skulls found in Danish waters in the period 1992-1996. Forensic Sci Int 2001;123:150-158.

7. Liang XH, Tang YL, Luo E, Zhu GQ, Zhou H, Hu J, Tang XF, Wang XY: Maxillofacial injuries caused by the 2008 Wenchuan earthquake in China. J Oral Maxillofac Surg 2009;67:1442-1445.

8. Kvaal SI, Kolltveit K, Thomsen IO, Solheim T: Age estimation of adults from dental radiographs. Forensic Sci Int 1995;74:175-185.

9. Maber M, Liversidge HM, Hector MP: Accuracy of age estimation of radiographic methods using developing teeth. Forensic Sci Int 2006;159:S68-73.

10. Drusini AG, Toso O, Ranzato C: The coronal pulp cavity index: a biomarker for age determination in human adults. Am J Phys Anthropol 1997;103:353-363.

11. Gustafson G: Age determination on teeth. J Am Dent Assoc 1950;41:45-54. 
12. Vandevoort FM, Bergmans L, Cleynenbreugel JV, Bielen DJ, Lambrechts P, Wevers M, Peirs A, Willems G: Age calculation using x-ray microfocus computed tomographical scanning of teeth. A pilot study. J Forensic Sci 2004;49:787790.

13. Aboshi H, Takahashi T, Komuro T: Age estimation using microfocus $\mathrm{x}$-ray computed tomography of lower premolars. Forensic Sci Int 2010;200:35-40.

14. Jagannathan N, Neelakantan P, Thiruvengadam C, Ramani P, Premkumar P, Natesan A, Herald JS, Luder HU: Age estimation in an Indian population using pulp/tooth volume ratio of mandibular canines obtained from cone beam computed tomography. J Forensic Odontostomatol 2011;29:1-6.

15. Star H, Thevissen P, Jacobs R, Fieuws S, Solheim T, Willems G: Human dental age estimation by calculation of pulptooth volume ratios yielded on clinically acquired cone beam computed tomography images of monoradicular teeth. J Forensic Sci 2011;56:77-82.

16. Pinchi V, Pradella F, Buti J, Baldinotti C, Focardi M, Norelli GA: A new age estimation procedure based on the 3D CBCT study of the pulp cavity and hard tissues of the teeth for forensic purposes: a pilot study. J Forensic Leg Med 2015;36:150-157.

17. Akay G, Gungor K, Gurcan S: The applicability of Kvaal methods and pulp/tooth volume ratio for age estimation of the Turkish adult population on cone beam computed tomography images. Aust J Forensic Sci 2019;51:251-265.

18. Paewinsky E, Pfeiffer H, Brinkmann B: Quantification of secondary dentine formation from orthopantomograms - a contribution to forensic age estimation methods in adults. Int. J Legal Med 2005;119:27-30.

19. Erbudak HÖ, Ozbek M, Uysal S, Karabulut E: Application of Kvaal et al.'s age estimation method to panoramic radiographs from Turkish individuals. Forensic Sci Int 2012;219:141-146.

20. Koh KK, Tan JS, Nambiar P, Ibrahim N, Mutalik S, Khan Asif M: Age estimation from structural changes of teeth and buccal alveolar bone level. J Forensic Leg Med 2017;48:1521.

21. Bang G, Ramm E: Determination of age in humans from root dentin transparency. Acta Odontol Scand 1970;28:3-35.

22. Johanson G: Age determination in human teeth. Odontol Revy 1971;22:40-126.

23. Maples WR: An improved technique using dental histology for estimation of adult age. J Forensic Sci 1978;23:764-770.
24. Matsikidis G, Schulz P: Age determination by dentition with the aid of dental films. Zahnarztl Mitt 1982;72:7e8, 2524,2527-2528.

25. Solheim T: A new method for dental age estimation in adults. Forensic Sci Int 1993;59:137-147.

26. Olze A,Hertel J, Schulz R, Wierer T, Schmeling A: Radiographic evaluation of Gustafson's criteria for the purpose of forensic age diagnostics. Int $\mathrm{J}$ Legal Med 2012;126:615-621.

27. Singh N, Grover N, Puri N, Singh S, Arora S: Age estimation from physiological changes of teeth: a reliable age marker? J Forensic Dent Sci 2014;6:113-121.

28. John MK, Joseph VJ, Arul Dev DP, Sandeep L, Anulekh B, Anupama: Accuracy of age estimation in Kerala population using Gustafson's formula: a forensic evaluation IOSR J Dent Med Sci 2014;13:39-44.

29. Bajpai M, Pardhe N, Kumar M, Agrawal S: A comparative evaluation of Gustafson's formula and new formula for age estimation in India - a forensic study. Prague Med Rep 2015;116:203-209.

30. Karkhanis S, Mack P, Franklin D: Age estimation standards for a Western Australian population using the dental age estimation technique developed by Kvaal et al. Forensic Sci Int 2014;235:104.e1-e6.

31. Patil SK, Mohankumar KP, Donoghue M: Estimation of age by Kvaal's technique in sample Indian population to establish the need for local Indian-based formulae. J Forensic Dent Sci 2014;6:166-170.

32. Mittal S, Nagendrareddy SG, Sharma ML, Agnihotri P, Chaudhary S, Dhillon M: Age estimation based on Kvaal's technique using digital panoramic radiographs. J Forensic Dent Sci 2016;8:115.

33. Roh BY, Lee WJ, Ryu JW, Ahn JM, Yoon CL, Lee SS: The application of the Kvaal method to estimate the age of live Korean subjects using digital panoramic radiographs. Int J Legal Med 2018;132:1161-1166.

34. Li MJ, Chu G, Han MQ, Chen T, Zhou H, Guo YC: Application of the Kvaal method for age estimation using digital panoramic radiography of Chinese individuals. Forensic Sci Int 2019;301:76-81.

35. Arora J, Talwar I, Sahni D, Rattan V: Secondary dentin as a sole parameter for age estimation: comparison and reliability of qualitative and quantitative methods among North Western adult Indians. Egypt J Forensic Sci 2016;6:170-178.

36. Afify MM, Salem WS, Mahmoud NF: Age estimation from pulp/tooth area ratio of canines using cone-beam computed tomography image analysis: study of an Egyptian sample. J Forensic Res 2019;10:434. 